\title{
Profile of thyrotoxic patients presenting as pyrexia of unkown origin: An observational case study from a tertiary care hospital
}

\author{
Ahmad Pala N. ${ }^{1 *}$, Ashraf M. ${ }^{2}$, Bhoughal B. ${ }^{3}$ \\ DOI: https://doi.org/10.17511/ijmrr.2019.i01.06 \\ 1* Nazir Ahmad Pala, Lecturer, Department of Medicine, Government Medical College, Srinagar, Jammu and Kashmir, India. \\ 2 Mohd Ashraf, Assistant Professor, Department of Medicine, Government Medical College, Srinagar, Jammu and Kashmir, India. \\ 3 Badrinath Bhoughal, Associate Professor, Department of Medicine, Government Medical College, Srinagar, Jammu and Kashmir, India.
}

Objective: To study the profile of thyrotoxic patients evaluated for pyrexia of unknown origin (PUO). Methods: 25 patients, who were evaluated for pyrexia of unknown origin and found to have thyrotoxicosis as the cause for fever, were managed as per the recommended protocol and followed for 12 months. Results: All the patients were presumed to have infectious fever and had received antibiotics prior to diagnosis. Out of 25 patients, $20(80 \%)$ had subacute thyroiditis (SAT) and 5 (20\%) had hyperthyroidism (4 had Graves disease and 1 toxic adenoma). Patients with hyperthyroidism received thionamides and $\beta$ - blockers. $50 \%$ patients with subacute thyroiditis received analgesics, $25 \%$ received steroids only and $25 \%$ received a combination of analgesics and steroids. Early-onset transient hypothyroidism occurred in $40 \%$ patients with SAT, permanent hypothyroidism was less common and only $15 \%$ of patients were receiving levothyroxine therapy after one year of follow-up. Conclusion: Thyrotoxicosis should always be included in the differential diagnosis while evaluation of patients with PUO. Most of the patients with thyrotoxicosis are wrongly misinterpreted as infectious PUO and given unnecessary antibiotics. Early-onset transient hypothyroidism is common in SAT compared to permanent hypothyroidism. Although, symptomatic relief is achieved with analgesics and steroids but does not prevent the development of hypothyroidism.

Keywords: Thyrotoxic PUO, Acetylsalicylic, Corticosteroids, Post-thyroiditis hypothyroidism

Corresponding Author

Nazir Ahmad Pala, Lecturer, Department of Medicine, Government Medical College, Srinagar, Jammu and Kashmir, India.

Email: nazirpala2@gmail.com
How to Cite this Article

Pala NA, Ashraf M, Bhoughal B. Profile of thyrotoxic patients presenting as pyrexia of unkown origin: An observational case study from a tertiary care hospital. Int J Med Res Rev. 2019;7(1):30-35.

Available From

https://ijmrr.medresearch.in/index.php/ijmrr/article/ view/1032
To Browse

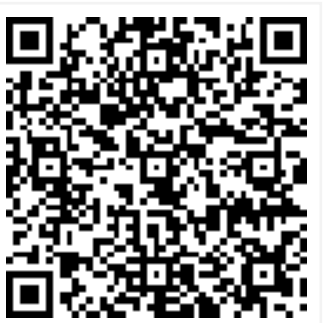

Manuscript Received 2019-01-16

Conflict of Interest No 2019-01-25

Funding $\mathrm{Nil}$
Review Round 2 2019-01-30

Ethical Approval Yes
Review Round 3

Plagiarism X-checker $6 \%$
Accepted 2019-02-05

Note

(C) 2019 by Nazir Ahmad Pala, Mohd Ashraf, Badrinath Bhoughal and Published by Siddharth Health Research and Social Welfare Society. This is an Open Access article licensed under a Creative Commons Attribution 4.0 International License https://creativecommons.org/licenses/by/4.0/ unported [CC BY 4.0]. 


\section{Introduction}

Fever is a symptom of prime importance as an indicator of a disease $[1,2]$ and may be the only symptom of a number of inflammatory, connective tissue and neoplastic diseases [3]. Sometimes it may not be possible to arrive at a diagnosis even after thorough evaluation for pyrexia. A number of endocrine diseases are accompanied by prolonged fever $[4,5,6]$. Although, fever is one of the symptoms of inflammatory processes in the thyroid gland, such as subacute thyroiditis [7, 8] and thyroid crisis. [9, 10], the manifestation of thyroid disease as fever alone is extremely rare. However, prolonged fever as the only manifestation of subacute thyroiditis (SAT) has been reported previously $[11,12,13]$. Subacute thyroiditis follows a triphasic course of thyrotoxicosis, hypothyroidism and subsequent restoration of euthyroidism in most of the patients [11, 14]. Rarely, hyperthyroidism (Graves's disease) can manifest with persistent fever for many months without clinical symptoms or signs to lead to suspicion of thyroid disease, which may become evident only after exhaustive investigation [15]. Symptomatic management with analgesics, beta blockers and sometimes with oral steroids in various pharmacological dosages cause rapid relief of pain and fever, in addition to the role in decreasing recurrence rate in subacute thyroiditis [16] whereas patients with hyperthyroidism are managed initially with thionamides and beta blockers [17]. This study was aimed to study the profile of thyrotoxic patients presenting as pyrexia of unknown origin and also to stress the need to evaluate thyroid function in patients being evaluated for pyrexia of unknown origin.

\section{Material and Methods}

This study was conducted in endocrine division of Department of medicine at a tertiary care hospital in north India

Study design: Prospective observational case study.

Inclusion criteria: Patients who were evaluated for pyrexia of unknown origin (PUO) and found to have thyrotoxicosis as the only cause for fever

Exclusion criteria: Patients with thyrotoxicosis associated with other major causes of PUO, including infections, neoplasms and connective tissue disorders were excluded.
Study subjects and data-variables: 25 patients who were evaluated for pyrexia of unknown origin (PUO) and found to have thyrotoxicosis as the cause for fever, underwent thorough clinical, biochemical and immunological evaluation, apart from thyroid function tests, which were performed prior to recruitment. The study subjects were managed as per the recommended protocol and followed for 12 months. TSH, T4 and T3 were measured by using commercial chemiluminescent immunoassays (Beckman Coulter Unicel, DXI). The normal range for T3, T4, and TSH as provided by manufacturers of kits is $(0.7-2.5 \mathrm{ng} / \mathrm{ml}),(3.5-13.59 \mu \mathrm{g} / \mathrm{dl})$, and (0.5-6.5mIU/L) for RIA respectively. Anti-TPO Antibody was measured using ECL kits from Roche (Germany) with normal range being 0.0-60.0 IU/L. Subjects with value of $>60.0 \mathrm{IU} / \mathrm{L}$ were considered as anti-TPO antibody positive. Patients with hyperthyroidism received thionamides and $\beta$ blockers and those with subacute thyroiditis received either analgesics or steroids alone or a combination of analgesics and steroids in variable doses as per the clinical status of patients, in addition to $\beta$-blockers used to alleviate hyper adrenergic symptoms. Patients were followed closely for the clinical status and thyroid function with repeat thyroid function every 6 weeks for the first 3 months and then 3 monthly for 12 months.

Statistical analysis: The statistical software SPSS 20 was used to analyse the data. Data were presented as mean \pm SD and $n(\%)$. The Parametric and non-parametric tests have been used to analyse the data after verifying the distribution of variables with the help of Shapiro-Wilk test.

\section{Results}

\section{Clinical Profile}

Mean age (years) of patients was $32.20 \pm 11.28$, $18(72 \%)$ were women and $7(28 \%)$ were men.

Symptoms: A history of preceding upper respiratory tract infection was noted in 12(60\%) 1-4 weeks before the onset of SAT. Out of 20 patients with SAT, thyroid pain was noted in 14 (70\%). Radiation of pain to jaw was noted in 10 (50\%) and dysphagia in $8(40 \%)$. Out 25 patients with thyrotoxicosis, tremor was recorded in 18 (72\%), sweating in $7(28 \%)$ and weight loss in $10(40 \%)$.

Signs: All the patients in our study were febrile with a temperature between $37 \mathrm{C}$ and 38 in 15 (60\%), and between $38 \mathrm{C}$ and $39 \mathrm{C}$ in 10 (40\%). 
Out of 25 patients, all the 4 patients with grave's disease had a symmetrical non tender goiter, one had a thyroid nodule. Out of 20 patients with SAT, goiter was noted in $6(30 \%)$, thyroid tenderness was noted in $16(80 \%)$

\section{Laboratory and imaging data}

Laboratory and imaging data is shown in Table-1: Major causes of PUO including infections, neoplasms and connective tissue disorders were excluded by negative haematological, microbiological, immunological and imaging studies. Thyroid peroxidase antibodies were measured in all patients and were in positive in 10 (40\%) patients. Iodine 131 thyroid scanning was performed in all, thyroid was not visualised or poorly visualised in all patients with SAT, homogenously increased uptake in patients with grave's disease and increased localised uptake with poorly visualised rest of the gland in 1 patient with toxic adenoma. Thyroid ultrasonography was done in 18 out 25 patients, which revealed mild thyroid enlargement with inhomogeneous echo texture and hypoechoic areas in 13 patients consistent with inflammation, diffuse hyperechogenicity in 4 patients with Grave's disease and localised hyperechogenicity with rest of the hypoechoic gland in 1 patient with toxic adenoma. Fine-needle aspiration biopsy of the thyroid was done in 13 patients: results for 11 patients were typical for SAT; and for 2, results were consistent with Hashimoto thyroiditis.

Table-1: Laboratory parameters at diagnosis in 25 patients with thyrotoxic PUO

\begin{tabular}{|c|c|c|c|}
\hline Parameter & $\begin{array}{l}\text { Subacute thyroiditis } \\
(n=20) \text { Mean } \pm \text { SD }\end{array}$ & $\begin{array}{l}\text { Hyperthyroidism(n } \\
=5) \text { Mean } \pm \text { SD }\end{array}$ & $\begin{array}{l}\text { Referenc } \\
\text { e range }\end{array}$ \\
\hline $\mathrm{TSH}(\mu \mathrm{IU} / \mathrm{ml})$ & $0.011 \pm 0.024$ & $0.013 \pm 0.029$ & $0.5-6.5$ \\
\hline $\mathrm{T} 4(\mu \mathrm{g} / \mathrm{dl})$ & $14.93 \pm 1.49$ & $15.98 \pm 1.23$ & $3.5-13.59$ \\
\hline T3(ng/dl) & $3.20 \pm 0.32$ & $3.17 \pm 0.39$ & $0.7-2.5$ \\
\hline $\begin{array}{l}\text { Anti- } \\
\text { TPO(IU/ml) }\end{array}$ & $120 \pm 65$ & $450 \pm 245$ & $0.0-60.0$ \\
\hline $\operatorname{ESR}(\mathrm{mm} / \mathrm{h})$ & $56 \pm 32$ & $34 \pm 18$ & $0-30$ \\
\hline \begin{tabular}{|l|} 
Uptake of \\
Iodine131 (\%)
\end{tabular} & $3.5 \pm 3.2$ & $40 \pm 25$ & $5-25$ \\
\hline
\end{tabular}

Data expressed as mean \pm SD

Table-2: Therapy of 25 patients with
thyrotoxic PUO

\begin{tabular}{|l|l|l|}
\hline \multirow{2}{*}{ Therapy } & \multicolumn{2}{|c|}{ Patients } \\
\cline { 2 - 3 } & $n$ & $\%$ \\
\hline Analgesics only & 10 & $50 \%$ \\
\hline Corticosteroids only & 5 & $25 \%$ \\
\hline Analgesics+ Steroids & 5 & $25 \%$ \\
\hline
\end{tabular}

\begin{tabular}{|l|l|l|}
\hline Neomercazole & 5 & - \\
\hline Radioiodine Ablation & 1 & - \\
\hline
\end{tabular}

Data expressed as n (\%)

Table 2 shows the types of therapies for the patients. Among 20 patients of SAT, 10 patients received analgesics (Acetylsalicylic acid), out of which 6 patients had relief of pain, fever and thyroid tenderness within a mean of 14 days, 5 patients received prednisolone $40 \mathrm{mg} /$ day for 10 days which was tapered over 3 weeks and had relief of clinical manifestations within a mean of 10 days, and 5 patients who did not respond to analgesics alone were given a combination of analgesics and corticosteroids( $40 \mathrm{mg} /$ day which was tapered over 3 weeks) and had relief within a mean of 12 days from the start of therapy. 5 patients with hyperthyroidism (4 patients with Grave's disease and 1 patient with toxic Adenoma) were given neomercazole (30 mg/day) initially, later on adjusted as per the clinical and thyroid profile. One patient with toxic adenoma was subsequently given radio-iodine ablation. 18 patients received $\beta$-blockers for the relief of hyper adrenergic symptoms.

Table-3: Outcome of 25 patients with thyrotoxic PUO

\begin{tabular}{|l|l|}
\hline \multicolumn{1}{|c|}{ Outcome } & \multicolumn{1}{c|}{ Patient n (\%) } \\
\hline Transient hypothyrodism & $8(40 \%)$ \\
\hline Permanent hypothyrodism & $3(15 \%)$ \\
\hline
\end{tabular}

Data expressed as n (\%)

Patients were followed with a repeat thyroid function after 6 weeks. In patients with SAT, transient hypothyroidism was noted in $8(40 \%)$, with a TSH of upto $10 \mathrm{mIU} / \mathrm{liter}$ in 4 and upto 15 $\mathrm{mIU} /$ liter in 4 patients. Repeat thyroid function at 3 months revealed normalisation of TSH in those with TSH of upto $10 \mathrm{mIU} /$ liter, 3 out of 4 patients with initial TSK of more than $10 \mathrm{mIU} /$ liter persisted with $\mathrm{TSH}$ more than $10 \mathrm{mIU} / \mathrm{liter}$ at 6 months and were given levothyroxine (50 $\mathrm{mcg} /$ day $)$ in view of symptoms of hypothyroidism. At 9 and 12 months, normal TSH was noted in both categories and the latter group was continued on levothyroxine. Patients with hyperthyroidism (4 with Grave's disease and 1 with toxic adenoma) who were given neomercazole (30 mg/day) were re-assessed with a repeat thyroid function at 3, 6, 9 and 12 months, all patients with Grave's hyperthyroidism had normal T4 and T3 till 1 year of follow-up. The patient with toxic adenoma was given radioiodine ablation after 3 months of diagnosis with documented normalisation of T4 and T3 at regular intervals. 


\section{Discussion}

The maintenance of body temperature in humans within a narrow range is due to interplay of intricate homeostatic mechanisms. The infectious fever is as result of elevation of the hypothalamic "set point" which causes homeostatic mechanisms to raise body temperature and is not because of failure of thermoregulation [18.19]. Defective thermoregulation may cause fever in other circumstances like heat stroke, malignant hyperthermia of anaesthesia and hypothalamic disorders [20].

Since hormonal mechanisms are important in thermoregulation, therefore, various endocrine disorders like thyroiditis, hyperthyroidism, Addison's disease, pheochromocytoma, primary hyperparathyroidism and hypoglycaemia can produce fever in man [21, 22]. The pathogenesis of fever in thyrotoxicosis is not completely understood yet. Although, thyroid hormone is known to be calorigenic, the precise mechanism for this thermogenesis is still debated, and is widely believed to be due to stimulation of the membranebound sodium-potassium ATPase (sodium pump) [23].

Heat intolerance and an increased basal metabolic rate are common in hyperthyroidism. The true incidence and grade of fever in uncomplicated hyperthyroidism has not been determined and, if present, is usually of low grade in most patients, however, high fever is a common feature of thyroid storm The patients with subacute thyroiditis may have impressive fever with only slightly elevated or even normal circulating levels of thyroid hormone. In such cases, fever probably results from actual inflammation of the thyroid gland, as evidenced by pain, tenderness and increased sedimentation rates [24]. In our thyrotoxic patients, $60 \%$ had temperature between $37-38^{\circ} \mathrm{C}$ and $40 \%$ had temperature between $38-39^{\circ} \mathrm{C}$.

Subacute thyroiditis is the commonest cause of fever with a tender thyroid [25]. Symptoms of thyroiditis usually follow an upper respiratory tract infection, thyroid pain and tenderness is found in about $90 \%$ of patients. Pain may be referred to the lower jaw, ear or occiput, but in some patients the typical features are absent and the presentation is simply one of prolonged fever, significant weight loss and no local symptoms [26, 27].
In our study, a history of preceding upper respiratory tract infection was noted in $12(60 \%) 1$ 4 weeks before the onset of SAT. Out of 20 patients with SAT, thyroid pain and tenderness was noted in $14(70 \%)$, radiation of pain to jaw was noted in 10 (50\%) and dysphagia in $8(40 \%)$. Out 25 patients with thyrotoxicosis, tremor was recorded in $18(72 \%)$, sweating in $7(28 \%)$ and weight loss in $10(40 \%)$. Out of 25 patients, 4 patients with grave's disease had a symmetrical non tender goiter and one had a thyroid nodule.

There is no definitive cure for painful SAT, but there is effective treatment to ameliorate the symptoms and to allow the disease to run its course in an asymptomatic fashion. Salicylates and NSAIDs can be given to patients with mild and moderate forms of the disorder [17]. In severe forms, therapy with corticosteroids generally provides rapid relief of symptoms within 24-48 h [17]. Prednisone therapy may be initiated in dosages of $40 \mathrm{mg}$ daily, with a gradual reduction in dosage thereafter over several weeks [17]. Analgesics or corticosteroids alone or in combination given in $80 \%$ patients relieved local symptoms in most of the patients with SAT within 2 weeks.

Transient early hypothyroidism and late-onset (or permanent) hypothyroidism can occur in patients with SAT $[28,29,30,31]$. Initial thyrotoxic phase is often followed by a transient phase of hypothyroidism, which is believed to be the result of exaggerated TSH response to TSH-releasing hormone. Similarly, post-thyroiditis, permanent hypothyroidism has also been noted in upto $5 \%$ of patients [28]. In the current study, $40 \%$ patients had early transient hypothyroidism with persistent TSH elevation of more $10 \mathrm{mIU} /$ liter in $15 \%$ patients beyond 3 months, without significant relationship to steroid therapy. 3 out of 4 patients with postthyroiditis hypothyroidism were put on levothyroxine beyond 3 months, in view of symptoms of hypothyroidism and were on levothyroxine till last follow-up at 12 months.

SAT, which is considered to be a viral disease [32, $33,34]$, rarely recurs after a complete recovery, possibly because of immunity to the offending virus. However, late recurrence after several years has been reported $[35,36,37,38]$. In the current study, none of our patients with SAT had recurrence within one year of follow-up. Patients with hyperthyroidism (4 with Grave's disease and 1 with toxic adenoma) were treated with neomercazole (30 $\mathrm{mg} /$ day) initially. 
Subsequently patient with toxic adenoma was radioablated. All the five patients were euthyroid at one year of follow-up.

\section{Conclusion}

In conclusion, patients with subacute thyroiditis and hyperthyroidism can present with fever alone or in combination with local symptoms and features of thyrotoxicosis. Thyrotoxicosis should be considered during evaluation in patients with pyrexia of unknown origin (PUO), in addition to infectious, neoplastic and other non-infectious inflammatory aetiologies. Acetylsalicylic or corticosteroids alone or in combination in patients with subacute thyroiditis (SAT) provide significant relief of symptoms in patients with SAT. Early transient hypothyroidism is common in SAT and corticosteroids do not significantly decrease the incidence of transient or permanent hypothyroidism.

\section{Authors' contributions}

The project idea was conceived by Nazir Ahmad Pala, who also drafted the manuscript. Data was collected by Mohd Ashraf Gojri and Badrinath Bougal Statistical Analysis was done by Nazir Ahmad Pala. All co-authors contributed to the manuscript and gave valuable suggestions for final drafting of manuscript. All authors read and approved the final manuscript.

\section{Reference}

01. Phair JP. Fever. Arch Intern Med. 1979 Nov;139(11)1219.

[Crossref]

02. Musher DM, Fainstein V, Young EJ, et al. Fever patterns, Their lack of clinical significance. Arch Intern Med. 1979 Nov;139(11)1225-8.

[Crossref]

03. Aduan RP, Fauci AS, Dale DC, et al. Factitious fever and self-induced infection- a report of 32 cases and review of the literature. Ann Intern Med. 1979 Feb;90(2)230-42.

[Crossref]

04. Buckley RM. Miscellaneous and unusual causes of FUO, In- Murray, HW (ed) FUO- Fever of Undetermined Origin. Future, London. 1983;109-122.

[Crossref]
05. PEO--pyrexia of endocrine origin. Lancet. 1979 Aug $4 ; 2(8136) 236-7$.

[Crossref]

06. Simon HB, Daniels GH. Hormonal hyperthermiaendocrinologic causes of fever. Am J Med. 1979 Feb;66(2)257-63.

[Crossref]

07. Levine SN. Current concepts of thyroiditis. Arch Intern Med. 1983 Oct;143(10)1952-6.

[Crossref]

08. Dalovisio JR, Blonde L, Cortez LM, Pankey GA. Subacute thyroiditis with increased serum alkaline phosphatase. Ann Intern Med. $1978 ; 88 ; 505-507$.

[Crossref]

09. Rawson RW. Hyperthyroidism, Disease-a-Month. The Year Book Publishers, Chicago. Apr 1955. [Crossref]

10. McArthur JW, Rawson RW, Means JH, Cope O. Thyrotoxic crisis. JAMA. 1947;134;864-874. [Crossref]

11. Farwell AP, Braverman LE. Inflammatory thyroid disorders. Otolaryngol Clin North Am. 1996 Aug;29(4)541-56.

[Crossref]

12. Sambit D. Subacute thyroiditis- An uncommon cause of fever of unknown origin. Indian Journal of Endocrinology and Metabolism. 2012;16(8)340-1.

[Crossref]

13. Volpé R, Row VV, Ezrin C. Circulating viral and thyroid antibodies in subacute thyroiditis. J Clin Endocrinol Metab. 1967 Sep;27(9)1275-84. [Crossref]

14. Kitchener MI, Chapman IM. Subacute thyroiditis- a review of 105 cases. Clin Nucl Med. 1989 Jun;14(6)439-42.

[Crossref]

15. Yechiel S, Yecheskel S, Tsila Z. Graves' disease presenting as pyrexia of unknown origin. Postgraduate Medical Journal. 1988(64)209212.

[Crossref]

16. Raupach T, Karaus M. Pharyngitis, massive ESR elevation and hyperthyroidism in a 71-year-old female patient. Internist (Berl). 2004 Oct;45(10)1182-8.

DOI: $10.1007 / \mathrm{s} 00108-004-1259-7 \quad$ [Crossref] 
17. Volpé R. The management of subacute (DeQuervain's) thyroiditis. Thyroid. 1993;3(3)253-5.

[Crossref]

18. Atkins E, Bodel P. Fever. N Engl J Med. 1972 Jan 6;286(1)27-34.

DOI:10.1056/NEJM197201062860109 [Crossref]

19. Dinarello CA, Wolff SM. Pathogenesis of fever in man. N Engl J Med. 1978 Mar 16;298(11)60712.

[Crossref]

20. Simon HB. Extreme pyrexia. JAMA. 1976 Nov $22 ; 236(21) 2419-21$.

[Crossref]

21. Buckley RM. Miscellaneous and unusual causes of FUO, In- Murray, HW (ed) FUO- Fever of Undetermined Origin. Futura, London. 1983;109- 122.

[Crossref]

22. Kreisberg R A, Owen W C, Siegal A M. Nutrition and endocrine disease. Med Clin North Am. 1970 Nov;54(6)1473-94.

[Crossref]

23. Izmail-Beigi $F$, Edelman IS. Mechanism of thyroid calorigenesis- role of active sodium transport. Proc Natl Acad Sci U S A. 1970 Oct;67(2)1071-8.

[Crossref]

24. Mcarthur JW, Rawson RW. Thyrotoxic crisis- an analysis of the thirty-six cases at the Massachusetts General Hospital during the past twenty-five years. J Am Med Assoc. 1947 Jul 5;134(10)868-74.

[Crossref]

25. Pearce EN, Farwell AP, Braverman LE. Thyroiditis. N Engl J Med. 2003 Jun 26;348(26)2646-55.

DOI: $10.1056 /$ NEJMra021194 [Crossref]

26. Singer PA. Thyroiditis, Acute, subacute, and chronic. Med Clin North Am. 1991 Jan;75(1)6177.

[Crossref]

27. Chiovato L, Martino E. Thyroiditis, In- Pinchera $A$, ed, Endocrinology and Metabolism. LondonMc Graw-Hill International (UK) Ltd. 2001;1899.

[Crossref]
28. Gozariu L, Stroe M, Vladutiu T, et al. Late hypothyroidism following subacute thyroiditis. Exp Clin Endocrinol. 1986 Jun;87(1)48-52. [Crossref]

29. Iitaka M, Momotani N, Hisaoka T, et al. TSH receptor antibody-associated thyroid dysfunction following subacute thyroiditis. Clin Endocrinol (Oxf). 1998 Apr;48(4)445-53.

[Crossref]

30. Lio S, Pontecorvi A, Caruso M, et al. Transitory subclinical and permanent hypothyroidism in th e course of subacute thyroiditis (de Quervain). Acta Endo (Copenh). 1984 May;106(1)67-70. [Crossref]

31. Tikkanen MJ, Lamberg BA. Hypothyroidism following subacute thyroiditis. Acta Endocrinol (Copenh). 1982 Nov;101(3)348-53.

[Crossref]

32. Brouqui $P$, Raoult $D$, Conte-Devolx B. Coxsackie thyroiditis. Ann Intern Med. 1991 Jun 15;114(12)1063-4.

[Crossref]

33. Volpé R, Row VV, Ezrin C. Circulating viral and thyroid antibodies in subacute thyroiditis. J Clin Endocrinol Metab. 1967 Sep;27(9)1275-84. [Crossref]

34. Sato M. Virus-like particles in the follicular epithelium of the thyroid from a patient with subacute thyroiditis (De Quervain). Acta Pathol Jpn. 1975 Jul;25(4)499-501.

[Crossref]

35. Tauveron I, Thieblot $P$, Marcheix JC. Recurrence after 12 years of de Quervain-Crile subacute thyroiditis [French]. Rev Med Interne. $1991 ; 12 ; 396$.

[Crossref]

36. Bauman A, Friedman A. Recurrent subacute thyroiditis- a report of three cases. $\mathrm{N} Y$ State J Med. 1983 Jun;83(7)987-8.

[Crossref]

37. Iitaka M, Momotani N, Ishii J, et al. Incidence of subacute thyroiditis recurrences after a prolonged latency- 24-year survey. J Clin Endocrinol Metab. 1996 Feb;81(2)466-9. [Crossref]

38. Yamamoto $M$, Saito $S$, Sakurada T, Tamura $M$, Kudo $Y$, Yoshida K, et al. Recurrence of subacute thyroiditis over 10 years after the first attack in three cases. Endocrinol Jpn. 1988;35;833-839.

[Crossref] 